\title{
Adhesion of Polyethylene/Polyethylene Terephthalate (PE/PET) Laminated Sheets by Homogeneous Low Potential Electron Beam Irradiation (HLEBI) Prior to Assembly and Hot-Press above Melting Point
}

\author{
Sagiri Takase ${ }^{1, *}$, Helmut Takahiro Uchida ${ }^{1,2}$, Arata Yagi ${ }^{1, *}$, Masae Kanda ${ }^{3}$, Olivier Lame ${ }^{4}$, \\ Jean-Yves Cavaille ${ }^{4}$, Yoshihito Matsumura ${ }^{1}$ and Yoshitake Nishi ${ }^{1}$ \\ ${ }^{1}$ School of Engineering, Tokai University, Hiratsuka 259-1292, Japan \\ ${ }^{2}$ Imaging Center for Advanced Research (TICAR), Tokai University, Hiratsuka 259-1292, Japan \\ ${ }^{3}$ Center of Applied Superconductivity \& Sustainable Energy Research, Chubu University, Kasugai 487-8501, Japan \\ ${ }^{4}$ MATEIS, INSA Lyon, Bât. B. Pascal, $5^{\circ}$ étage, 7, Avenue Jean Capelle, 69621 Villeurbanne cedex France
}

2-layer laminated sheets (PE/PET) with Polyethylene (PE) and Polyethylene Terephthalate (PET) were prepared by a new adhesion method, a double-step treatment consisting of applying low dose ( $\leqq 1.30 \mathrm{MGy})$ homogeneous low energy electron beam irradiation (HLEBI) prior to hot-press under $5 \mathrm{MPa}$ and $403 \mathrm{~K}$. Although the weak hot-press adhesion of the PE/PET was observed without HLEBI, the new adhesion mostly raised the bonding force at interface as evidenced by the mean adhesive force of peeling resistance $\left({ }^{\circ} F_{\mathrm{p}}\right)$. Based on the 3 -parameter Weibull equation, the lowest ${ }^{\circ} F_{\mathrm{p}}$ value at peeling probability $\left(P_{\mathrm{p}}\right)$ of zero $\left(F_{\mathrm{s}}\right)$ could be estimated. An increasing trend in $F_{\mathrm{s}}$ occurred by the double-step treatment applying HLEBI up to $1.08 \mathrm{MGy}$ reaching a maximum at $16.0 \mathrm{~N} \cdot \mathrm{m}^{-1}$, improving the safety level without radiation damage. When HLEBI cut the chemical bonds in PE and PET, and generated terminated atoms with dangling bonds, they probably induced the chemical bonding. Therefore, increasing adhesion energy between the laminated sheets could be explained. [doi:10.2320/matertrans.M2016460]

(Received December 27, 2016; Accepted April 10, 2017; Published May 19, 2017)

Keywords: joint, adhesion, electron beam, irradiation, polyethylene (PE), polyethylene terephthalate (PET)

\section{Introduction}

In recent years, polymer materials are highly anticipated field of medical treatment or industrial product. Particularly, polymers have much attention due to its low cost and high toughness. In this research, we focused on Polyethylene (PE) and Polyethylene Terephthalate (PET). PE exhibits high wear resistance and high strength as well as transparency. ${ }^{1)}$ PET has a reputation of being able to gas barrier property and insulation, but difficult adhesives. In other words, it indicates that we can project use in the semiconductor field.

In order to joint different polymers, methods such as glued joints $^{2)}$, welding joints ${ }^{2)}$, or corona treatment method ${ }^{3)}$ have been reported. From the industrial point of view, the homogeneous low energy electron beam irradiation (HLEBI) treatment is established method with wide material selectivity. Nevertheless, the application of HLEBI to jointed different polymers has not been argued sufficiently for now. Therefore, this work is aimed to confirm the effectiveness of HLEBI on the joining for different kinds of polymers, combining with the heat welding.

According to past studies in our group, HLEBI improves the mist resistance and wetting of inorganic materials, ${ }^{4)}$ and increases polymer adhering to glass fibers raising impact strength in GFRP. ${ }^{5)}$

Applying surface treatment of low dose of electron beam irradiation on the order of 0.01 to $1 \mathrm{MGy}$ has been gaining momentum as a successful method to adhere polymeric materials without the use of glues.

HLEBI has been found to increase adhesive mechanical properties of polymer-polymer laminations for biomedical

*Graduate Student, Tokai University applications of PDMS (polydimethylsilozane)/PTFE (polytetrafluoroethylene) $^{6)}$, PDMS/PP (polypropylene) ${ }^{7)}$, and then create strong adhesion of PTFE/PE. ${ }^{8)}$

Improvements are mainly caused by the irradiation with the formation of dangling bonds at terminated atoms in polymers. ${ }^{9)}$ Dangling bonds enhance the surface energy, which is probably the mechanism for joining the different polymers. ${ }^{10)}$

On the other hand, the effects of the temperature condition of hot-press after HLEBI treatment on adhesive mechanical properties has not been sufficiently studied for the PE/PET lamination.

Hot-press at elevated temperatures to just above melting point under effective pressure of $5 \mathrm{MPa}$ probably induces the tangling of each polymer of PE and PET. In addition, when active electrons of terminated atoms in each polymer on PE and PET surface exist, cross-linking with chemical bonds and intermolecular attractive force are probably generated. Since rapid and strong adhesion of PE/PET by using HLEBI prior to hot-press can be expected, the strong adhesion of the PE/ PET lamination treated by both HLEBI and hot-pressing at high temperature above melting point has been successfully developed in the present work.

Therefore, the effects of HLEBI prior to hot-press lamination above melting point of $\mathrm{PE}$ on the adhesive force of peeling resistance of bio-adaptable and high strength PE/PET laminated sheets have been investigated.

\section{Experimental Procedure}

2.1 Preparation of PE/PET laminated sheets by hotpress

Composite sheets were constructed with PET (polyethylene terephthalate $)$ film $(10 \mathrm{~mm} \times 40 \mathrm{~mm} \times 50 \mu \mathrm{m}$, Teijin $\mu$ 
Tetoron Film, Teijin DuPont Films, Japan) and PE (10 mm $\times$ $40 \mathrm{~mm} \times 80 \mu \mathrm{m}$, High-star PF 100, Star plastic Industry Inc., Japan). PE/PET composite film lamination was subsequently performed by the uni-directional hot-press at $403 \mathrm{~K}$ for 3.0 minutes under $5 \mathrm{MPa}$ after HLEBI.

\subsection{Homogeneous low energy electron beam irradiation (HLEBI)}

The PE/PET laminated sheets were irradiated by using an electron-curtain processor (Type CB250/30/20 mA, Energy Science Inc., Woburn, MA, Iwasaki Electric Group Co. Ltd. Tokyo $)^{8,11-14)}$ prior to hot-press. The specimen was homogeneously irradiated with the sheet HLEBI with low energy through a titanium thin film window attached to a $550 \mathrm{~mm}$ diameter vacuum chamber. A tungsten filament in a vacuum is used to generate the electron beam at a low energy (acceleration potential, $V: \mathrm{kV}$ ), of $170 \mathrm{keV}$ and irradiating current density $(I, \mathrm{~A} / \mathrm{m})$ of $0.0131 \mathrm{~A} / \mathrm{m}$.

Although the sheet electron beam generation is in a vacuum, the irradiated sample has been kept under protective nitrogen at atmospheric pressure. The distance between sample and window is $25 \mathrm{~mm}$. To prevent oxidation, the samples are kept in a protective atmosphere of nitrogen gas with a residual concentration of oxygen below $400 \mathrm{ppm}$. The flow rate of nitrogen gas is $1.5 \mathrm{~L} / \mathrm{s}$ at $0.1 \mathrm{MPa}$ nitrogen gas pressure.

The absorbed dose is controlled by the integrated irradiation time in each of the samples. Here, absorbed dose is corrected from irradiation dose by using an FWT nylon dosimeter of RCD radiometer film (FWT-60-00: Far West Technology, Inc. 330-D South Kellogg Goleta, California 93117, USA) with an irradiation reader (FWT-92D: Far West Technology, Inc. 330-D South Kellogg Goleta, California 93117, USA). The absorbed dose corresponded to irradiation dose is 0.0432 MGy at each irradiation, which is applied for only a short time $(0.23 \mathrm{~s})$ to avoid excessive heating of the sample; the temperature of the sample surface remains below $323 \mathrm{~K}$ just after irradiation. The sample in the aluminum plate holder $(0.15 \mathrm{~m} \times 0.15 \mathrm{~m})$ is transported on a conveyor at a speed of $10 \mathrm{~m} / \mathrm{min}$. The sheet HLEBI is applied intermittently. Repeated irradiations to both side surfaces of the samples are used to increase the total irradiation dose. The interval between the end of one period of irradiation and the start of the next operation is $30 \mathrm{~s}$. When the irradiation current $(I, \mathrm{~mA})$, the conveyor speed $(S, \mathrm{~m} / \mathrm{min})$ and number of irradiations $(N)$ are determined, the irradiated dosage is proportional to the yield value from the irradiation current $(I, \mathrm{~mA})$, the conveyor speed $(S, \mathrm{~m} / \mathrm{min})$, and number of irradiations $(N)$.

Based on the density $\left(\rho: \mathrm{kg} \cdot \mathrm{m}^{-3}\right)$ and irradiation voltage at the specimen surface $(V: \mathrm{kV})$, the penetration depth $\left(D_{\mathrm{th}}: \mathrm{m}\right)$ of HLEBI is expressed by the following equation. ${ }^{15)}$

$$
D_{\text {th }}=66.7 V^{5 / 3} / \rho
$$

Specimen surface electrical potential $(V)$ was mainly reduced going through the Ti window $\left(\Delta V_{\mathrm{Ti}}\right)$ and $\mathrm{N}_{2}$ gas atmosphere $\left(\Delta V_{\mathrm{N} 2}\right)$.

$$
V=170 \mathrm{keV}-\Delta V_{\mathrm{Ti}}-\Delta V_{\mathrm{N} 2}
$$

Based on eq. (2), the dropped potential values, $\Delta V_{\mathrm{Ti}}$ and $\Delta V_{\mathrm{N} 2}$ are estimated from the acceleration potential $(170 \mathrm{keV})$, the $13 \mu \mathrm{m}$ thickness $\left(T_{\mathrm{Ti}}\right)$ of the titanium window (density:
$4540 \mathrm{~kg} \cdot \mathrm{m}^{-3}$ ), and the $25 \mathrm{~mm}$ distance between the sample and the window $\left(T_{\mathrm{N} 2}\right)$ in the $\mathrm{N}_{2}$ gas atmosphere (density: $\left.\rho_{\mathrm{N} 2}=1.13 \mathrm{~kg} \cdot \mathrm{m}^{-3}\right)$.

$$
\begin{aligned}
V_{\mathrm{Ti}} & =\left(T_{\mathrm{Ti}} / \mathrm{D}_{\mathrm{thTi}}\right) \times 170 \mathrm{keV} \\
& =T_{\mathrm{Ti}} \rho_{\mathrm{Ti}} /\left[66.7 \times(170 \mathrm{keV})^{2 / 3}\right] \\
& =\left(13 \times 10^{-6} \mathrm{~m}\right) \times\left(4540 \mathrm{kgm}^{-3}\right) /\left[66.7 \times(170 \mathrm{keV})^{2 / 3}\right] \\
& =22.28 \mathrm{keV}
\end{aligned}
$$

$\triangle V_{\mathrm{N} 2}$

$=\left(T_{\mathrm{N} 2} / \mathrm{D}_{\mathrm{thiN} 2}\right) \times V_{\mathrm{Ti}}$

$=T_{\mathrm{N} 2} \rho_{\mathrm{N} 2} /\left[66.7 \times\left(170 \mathrm{keV}-\Delta V_{\mathrm{Ti}}\right)^{2 / 3}\right]$

$=\left(25 \times 10^{-3} \mathrm{~m} \times 1.13 \mathrm{kgm}^{-3}\right) /\left[66.7 \times(170 \mathrm{keV}-22.2 \mathrm{keV})^{2 / 3}\right]$

Since the dropped potential values are $28.8 \mathrm{keV}$ and $15.6 \mathrm{keV}$, the specimen surface electrical potential, $V$ is obtained to be $125.6 \mathrm{keV}$ as follows.

$$
V=170 \mathrm{keV}-22.2 \mathrm{keV}-15.2 \mathrm{keV}=132.6 \mathrm{keV}
$$

Given typical densities of PE and PET are $925 \mathrm{~kg} \cdot \mathrm{m}^{-3}$ and $1380 \mathrm{~kg} \cdot \mathrm{m}^{-3}$, respectively. Thus, using eq. (1), the HLEBI depth into the PE film and PET film were estimated to be $D_{\text {th }}=248 \mu \mathrm{m}$ and $D_{\text {th }}=167 \mu \mathrm{m}$, respectively. These calculated values are 2-3 times larger compared to the sample thickness condition applied in this work, which is $80 \mu \mathrm{m}$ and $50 \mu \mathrm{m}$, respectively. Namely, the HLEBI penetrated through the entire thickness.

\subsection{T-peeling and simple tensile tests}

Composite samples after hot-press under $5 \mathrm{MPa}$ at $403 \mathrm{~K}$ were prepared for the T-peeling test to evaluate the influence of HLEBI on the mean adhesion energy of peeling resistance $\left({ }^{\mathrm{o}} F_{\mathrm{p}}\right)$, as shown in Fig. 1. Peeling adhesive force $\left(F_{\mathrm{p}}\right)$ vs. peeling distance $\left(d_{\mathrm{p}}\right)$ curves were obtained by using a micro-load tensile tester (F-S Master-1K-2N, IMADA Co. Ltd., Japan) with a strain rate of $10 \mathrm{~mm} / \mathrm{min}$. ${ }^{6}$ Since the unit of the $F_{\mathrm{p}}$ was $\mathrm{N} \cdot \mathrm{m}^{-1}$, the ${ }^{\mathrm{o}} F_{\mathrm{p}}$ was used instead of the adhesive strength, whose units should be $\mathrm{N} \cdot \mathrm{m}^{-2}$. The sample condition of tensile test was as follows:

(1) The vertical length from the peeling contact point to the end of the sample was $5 \mathrm{~mm}$.

(2) The $E_{\mathrm{p}}$ was determined by using micro-load tensile tester. The ${ }^{\mathrm{o}} F_{\mathrm{p}}$ was estimated by the peeling load and experimental peeling width and length of 10 and $35 \mathrm{~mm}$, respectively. The initial distance before peeling $\left(d_{\mathrm{i}}\right)$ was defined at the start point of peeling force, which corresponds to the start point of the first relaxation. The $d_{\mathrm{i}}$ value is $\sim 1 \mathrm{~mm}$.

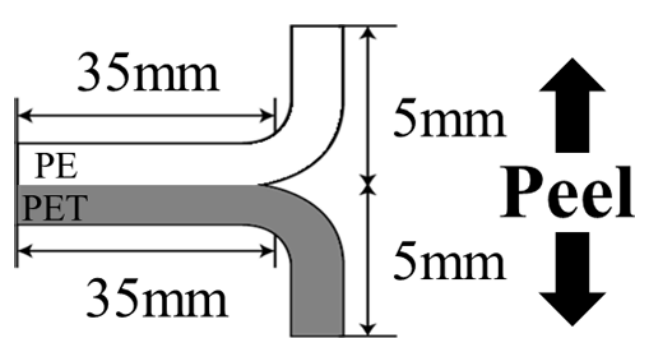

Fig. 1 Schematic diagram of T-Peeling test of the PE/PET laminated sheet. 
Focusing on the mechanical property of PE and PET sheets, a micro-load tensile teste (F-S Master-1K-2N, IMADA Co. Ltd., Japan) was also performed with a strain rate of $10 \mathrm{~mm} / \mathrm{min}$.

\subsection{X-ray photoelectron spectrometer (XPS) measure- ments}

Surface analysis by X-ray photoelectron spectrometer (XPS: Quantum 2000, ULVAC Co., JAPAN) ${ }^{6}$ has been performed for peeled PE and PET films with and without 1.08 MGy HLEBI. PE films contain the element of carbon (C), whereas PET films contain elements of $\mathrm{C}$ and oxygen (O). Narrow scans for the C (1s), O (1s) and N (1s) were performed, and appearance of those signals proved for $\mathrm{PE}$ and PET film surfaces.

\section{Results}

\subsection{Peeling load $\left(L_{\mathrm{p}}\right)$ - peeling distance $\left(d_{\mathrm{p}}\right)$ curve}

Figure 2 compares obtained $L_{\mathrm{p}}(\mathrm{N})$ vs. peeling distance, $d_{\mathrm{p}}$ $(\mathrm{mm})$ curves between HLEBI and untreated PE/PET laminated sheets at median accumulative probability of peeling force, $P_{\mathrm{p}}=0.50$. The adhesive force of peeling $\left({ }^{\circ} F_{\mathrm{p}}\right)$ was estimated by the peeling load and peeling distance curves from 10 to $30 \mathrm{~mm}$.

Although without HLEBI a large peeling load of peeling resistance in the PE/PET laminated sheets could not be obtained, by applying HLEBI at $1.08 \mathrm{MGy}$ the peeling load, $L_{\mathrm{p}}$ is significantly increased $(\sim 1.9 \mathrm{~N})$ over the low value of the untreated $(\sim 0.20 \mathrm{~N})$. The 1.08 MGy-HLEBI therefore laminates the PE with PET, generating the higher peeling resistance. Based on the optical scale observation, the fracture can be seen to always occur at the interface. The adhesion force is mainly caused by chemical bonds and adhesive area, while residual space sites invisible probably exists at adhesive interface.

\subsection{Adhesive force of peeling resistance $\left({ }^{\circ} F_{\mathrm{p}}\right)$ as a func- tion of peeling probability $\left(\boldsymbol{P}_{\mathbf{p}}\right)$}

Figure 3 plots the relationships between the adhesive force of peeling resistance $\left({ }^{\circ} F_{\mathrm{p}}\right)$ and cumulative probability of peeling $\left(P_{\mathrm{p}}\right)$ of the PE/PET laminated sheets untreated $(O)$ and HLEBI-treated with each dose. Increasing the hot-press temperature from $403 \mathrm{~K}$ tremendously strengthens the adhesive force of the peeling, about one order magnitude. Applying 1.08 MGy HLEBI with each dose from 0.22 to $1.30 \mathrm{MGy}$ ( $\bigcirc, \triangle, \square, \nabla,(\bigcirc)$ and $\diamond$ ) also gives the highest ${ }^{\circ} F_{\mathrm{p}}$ values, particularly above $P_{\mathrm{p}}>0.4$. Both hot-press and HLEBI additively improves the ${ }^{\mathrm{o}} F_{\mathrm{p}}$ because of strengthening mechanism shift by elevating the hot-press temperature

\subsection{Adhesive force of peeling resistance $\left({ }^{\circ} F_{\mathrm{p}}\right)$ as a func- tion of HLEBI-Dose}

Figure 4 shows changes in the ${ }^{\circ} F_{\mathrm{p}}$ for low-, median- and high- $P_{\mathrm{p}}$ of $0.06,0.50$ and 0.94 against HLEBI dose.

Comparing the adhesive force at high $P_{\mathrm{p}}\left(P_{\mathrm{p}}=0.94\right),{ }^{\circ} F_{\mathrm{p}}=$ $16.0 \mathrm{~N} \cdot \mathrm{m}^{-1}$ and ${ }^{\circ} F_{\mathrm{p}}=86.8 \mathrm{~N} \cdot \mathrm{m}^{-1}$ are obtained for untreated and 0.65 MGy-HLEBI samples, respectively. Thus, ${ }^{\circ} F_{\mathrm{p}}$ of 0.65 MGy-HLEBI samples are about 5.4 times larger compared to that of untreated samples.
Additionally, comparing at low $P_{\mathrm{p}}\left(P_{\mathrm{p}}=0.06\right)$, untreated samples at $0.85 \mathrm{~N} \cdot \mathrm{m}^{-1}, 1.08 \mathrm{MGy}$-HLEBI samples at $16.8 \mathrm{~N} \cdot \mathrm{m}^{-1}$. The obtained ${ }^{\circ} F_{\mathrm{p}}$ for $1.08 \mathrm{MGy}$-HLEBI samples reveals about 20 times larger ${ }^{\circ} F_{\mathrm{p}}$ compared to untreated samples. Furthermore, comparing at median $P_{\mathrm{p}}\left(P_{\mathrm{p}}=0.50\right)$, untreated samples at $3.02 \mathrm{~N} \cdot \mathrm{m}^{-1}, 1.08 \mathrm{MGy}$-HLEBI samples at $37.3 \mathrm{~N} \cdot \mathrm{m}^{-1}$. The obtained ${ }^{\circ} F_{\mathrm{p}}$ for $1.08 \mathrm{MGy}$-HLEBI samples shows about 12 times larger value compared to those of untreated samples. All ${ }^{\circ} F_{\mathrm{p}}$ values of PE/PET laminated sheets with small dose of 0.22 MGy to 1.30 MGy apparently exceed all corresponding values of untreated samples. Thus, adhesion of PE/PET laminated sheets with small dose from $0.22 \mathrm{MGy}$ to $1.30 \mathrm{MGy}-\mathrm{HLEBI}$ seems to be effective.

\subsection{Adhesive force of peeling resistance $\left({ }^{\circ} F_{\mathrm{p}}\right)$ as a func- tion of hot-press temperature}

Figure 5 plots the relationships between the adhesive force of peeling resistance $\left({ }^{\circ} F_{\mathrm{p}}\right)$ with $1.08 \mathrm{MGy}$ and reciprocal

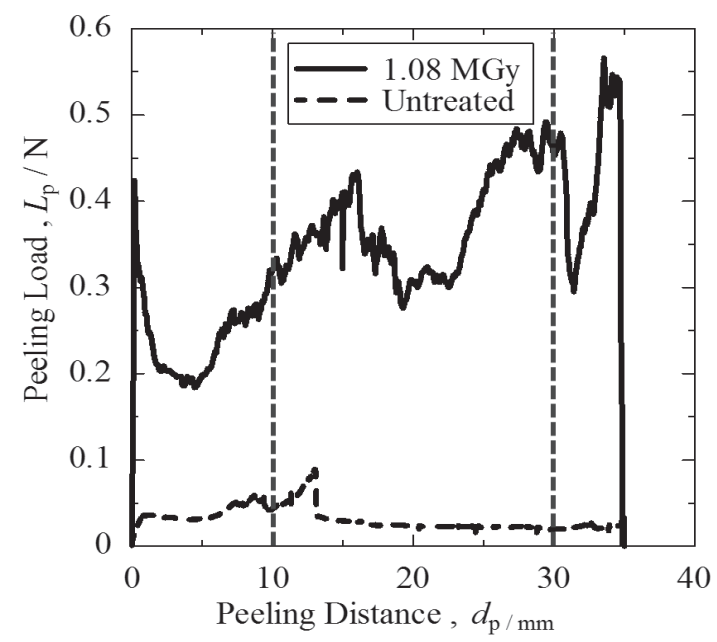

Fig. 2 Peeling load $\left(L_{\mathrm{p}}\right)$ - peeling distance $\left(d_{\mathrm{p}}\right)$ curves at $P_{\mathrm{p}}$ of 0.50 of PE/ PET laminated sheets untreated and treated by $1.08 \mathrm{MGy}-\mathrm{HLEBI}$ prior to assembly and hot-pressed at $403 \mathrm{~K}$.

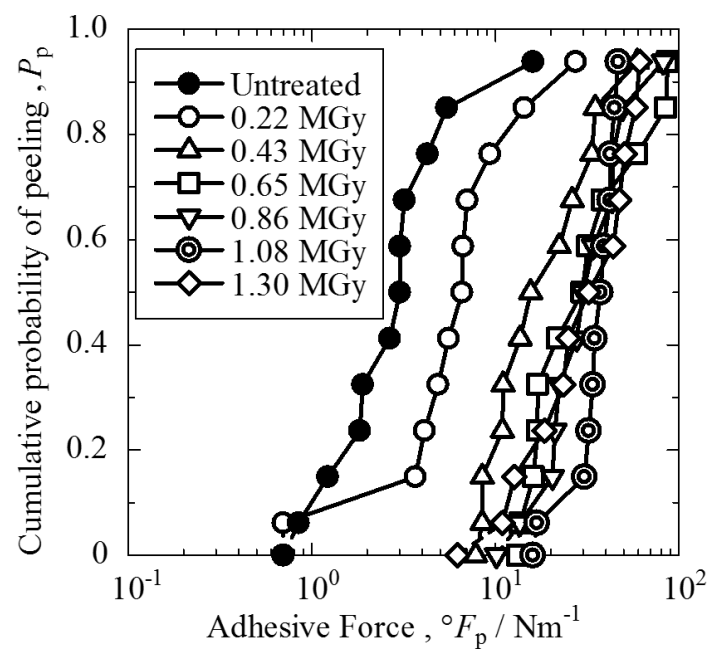

Fig. 3 Relationships between ${ }^{\circ} F_{\mathrm{p}}$ and $P_{\mathrm{p}}$ of PE/PET laminated sheets untreated and treated with different dose condition (0.22 MGy with hollow circles, 0.43 MGy with hollow triangles, 0.65 MGy with hollow squares, 0.86 MGy with hollow inverse triangles, $1.08 \mathrm{MGy}$ with double circles, and 1.30 MGy with hollow rhombic markers) prior to assembly and hotpressed at $403 \mathrm{~K}$ 


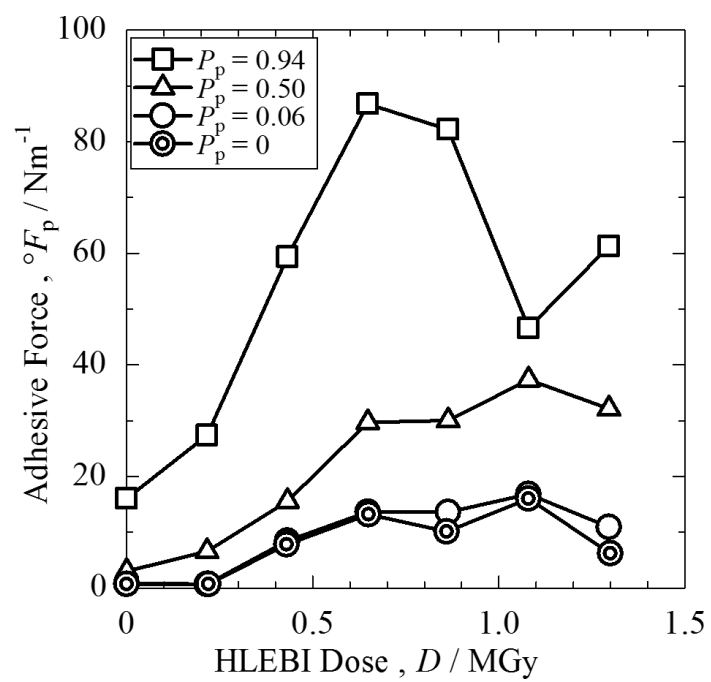

Fig. 4 Changes in experimental ${ }^{\circ} F_{\mathrm{p}}$ at low-, median-, and high- $P_{\mathrm{p}}$ of 0.06 (hollow circles), 0.50 (hollow triangles) and 0.94 (hollow squares) of PE/ PET laminated sheets against absorbed dose prior to assembly and hotpressed at $403 \mathrm{~K}$, together with calculated ${ }^{\circ} F_{\mathrm{p}}$ at the lowest $-P_{\mathrm{p}}$ of zero $\left({ }^{\circ} F_{\mathrm{s}}\right.$ ). Those for $P_{\mathrm{P}}=0$ (double circles) is also inserted in this figure, for comparison.

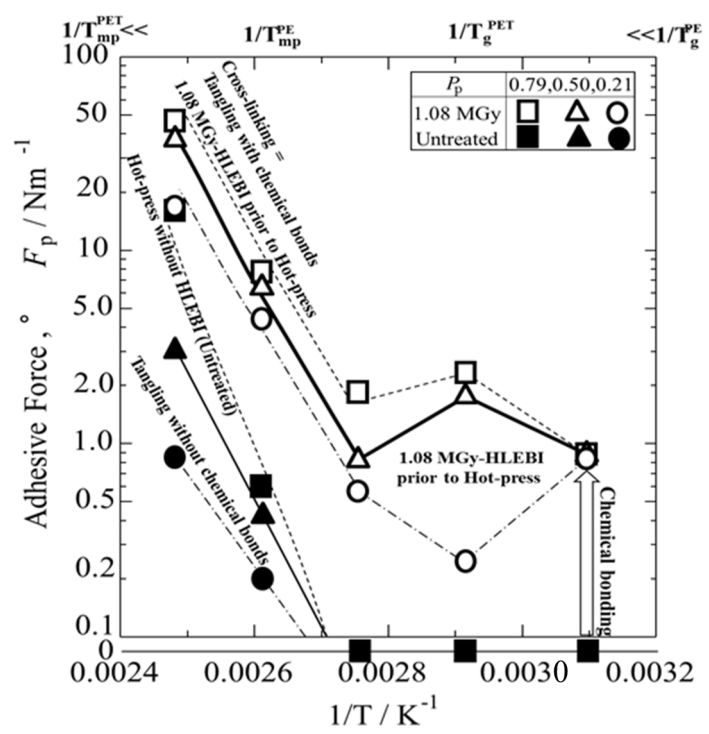

Fig. 5 Relationships between ${ }^{\circ} \mathrm{F}_{\mathrm{p}}$ and reciprocal temperature $(1 / \mathrm{T})$ of hotpress of PE/PET laminated sheets untreated $(\mathbf{O}, \mathbf{\Delta}, \mathbf{\square})$ and with $1.08 \mathrm{MGy}-\mathrm{HLEBI}(\bigcirc, \triangle, \square)$ prior to assembly.

temperature $(1 / \mathrm{T})$ of hot-press of PE/PET laminated sheets untreated $(\mathbf{O}, \boldsymbol{\Delta}, \boldsymbol{\square})$ and with $1.08 \mathrm{MGy}-\mathrm{HLEBI}(\bigcirc, \triangle$, $\square)$. Although adhesive forces cannot be detected below the melting point of polyethylene (PE) of about $388 \mathrm{~K}$ for $\mathrm{PE} /$ PET laminated sheets untreated $(\mathbf{O}, \boldsymbol{\Delta}, \mathbf{\square})$, the ${ }^{\circ} F_{\mathrm{p}}$ values can be detected at more than $388 \mathrm{~K}$, and increase at elevated temperatures.

On the other hand, the tremendous improvement of a large adhesive force with the plastic deformation was seen at each hot-press temperature above PE melting point for PE/PET laminated sheets irradiated with $1.08 \mathrm{MGy}$-dose $(\bigcirc, \triangle, \square)$. In addition, the adhesion at each hot-press temperature from melting point of PE $(388 \mathrm{~K})$ to even far below glass transition temperature of PET can be created without the large plastic deformation for PE/PET laminated sheets irradiated with
$1.08 \mathrm{MGy}$-dose $(\bigcirc, \triangle, \square)$.

\section{Discussion}

\subsection{Effects of hot-press at higher temperature on adhe- sion force}

As shown in Fig. 5 (plotted with markers of ( $\boldsymbol{\Delta}, \boldsymbol{\Delta}$ and

$\square)$, the strengthening the adhesive force induced by hotpress at $403 \mathrm{~K}$ is probably dominated by the tangling of PE/ PET polymers without chemical bonds at interface.

On the other hand, as shown in Fig. 5 (plotted with markers of $\bigcirc, \triangle$ and $\square$ ), the strengthening the adhesive force induced by HLEBI with hot-press is probably dominated by the density of cross-linking, that is, tangling of PE/PET polymers with chemical bonds at interface. Namely, the strengthening mechanism is apparently shifted by elevating the hotpress temperature of melting point of $388 \mathrm{~K}$ to over melting point of $403 \mathrm{~K}$, as shown in Fig. 5, is probably dominated by polymers tangling at the adhesion interface of hot-press of PE/PET laminated sheets untreated $(\mathbf{O}, \boldsymbol{\Delta}, \boldsymbol{\square})$ and with 1.08 MGy-HLEBI $(\bigcirc, \triangle, \square)$.

The dominant factor of the low temperature hot-press of the high adhesion force from 0.2 to $2.0 \mathrm{~N} / \mathrm{m}$ of PE/PET lamination treated by $1.08 \mathrm{MGy}-\mathrm{HLEBI}$ prior to hot-press from 322 to $362 \mathrm{~K}(\bigcirc, \triangle$ and $\square$ ) can be explained by the chemical bonds induced by dangling bonds except tangling.

Furthermore, the chemical bonding with slight tangling is probably attributed to the adhesion generation at each hotpress temperature from melting point of $\mathrm{PE}(388 \mathrm{~K})$ to $322 \mathrm{~K}$ of even far below glass transition temperature of PET for PE/ PET laminated sheets treated by 1.08 MGy-HLEBI $(O, \triangle$ and $\square$ ) prior to assembly and hot-press at $403 \mathrm{~K}$. When the intermolecular distance is enlarged by repulsive force between terminated atoms with dangling bonds, it is easy to tangle the PE to PET polymers.

Therefore, we conclude that the additive strengthening of tangling and cross-linking of tangling with chemical bonds can be induced by HLEBI and hot-press, respectively.

\subsection{X-ray photoelectron spectrometry (XPS) of PE and PET surface}

Figure 6 shows fracture surface analysis by X-ray photoelectron spectrometry (XPS) of oxygen $(\mathrm{O}(1 \mathrm{~s}))$ signals performed on the surface of PE and PET films which is created by peeling of PE/PET laminated sheets with and without 1.08 MGy previous HLEBI treatment. Results indicate the HLEBI acts to make adhesion in the PE/PET laminated sheets where fracture generally occurred near the peeled PEPET interface.

In Fig. 6 (a) the XPS narrow scan of O (1s) of the peeled $1.08 \mathrm{MGy}$ sample on PE surface shows peaks at $531.5 \mathrm{eV}$ corresponding with the $\mathrm{O}(1 \mathrm{~s})$ in $\mathrm{C}-\mathrm{O}$ groups. In order to calibrate the results in detail, XPS signals of $\mathrm{O}$ have been obtained for PE with and without HLEBI (solid and broken lines in Fig. 6 (a)). The highest intensity of C-O signal for untreated $\mathrm{PE}$ is gotten.

In Fig. 6 (b), the XPS narrow scan of O (1s) of the peeled $1.08 \mathrm{MGy}$ sample on PET surface shows peaks at $531.5 \mathrm{eV}$ corresponding with the $\mathrm{O}(1 \mathrm{~s})$ in $\mathrm{C}-\mathrm{O}$ group and $533 \mathrm{eV}$ in $\mathrm{C}=\mathrm{O}$ group. Applying calibration for the results in detail, the 

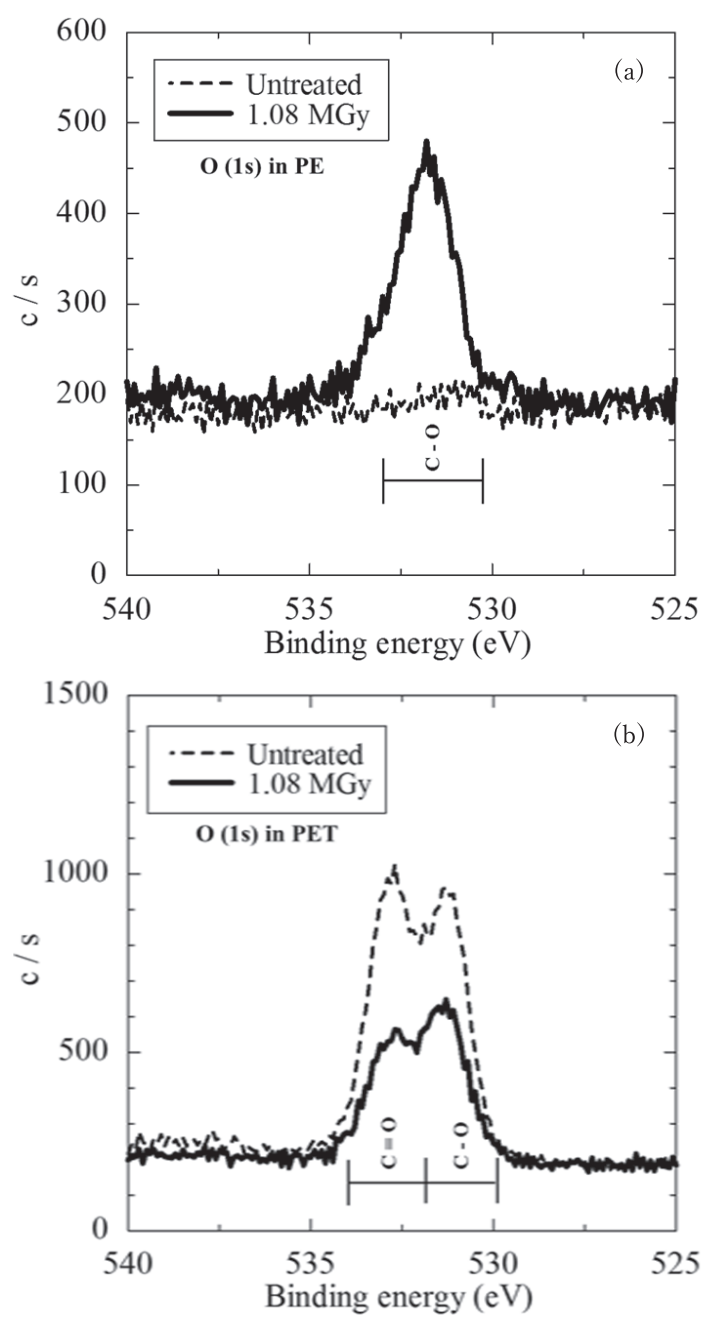

Fig. 6 Oxygen (1s) signal signals on PE and PET side peeled surface from XPS analysis PE/PET laminated sheets untreated and with 1.08 MGy-HLEBI prior to assembly and hot-pressed at $403 \mathrm{~K}$. The annotations inserted in the pictures give the binding energy range corresponding to single bond and double bond between $\mathrm{C}$ and $\mathrm{O}$, respectively. (a) $\mathrm{PE}$, (b) PET.

intensity of C-O peak of 1.08 MGy-HLEBI PET film after lamination (solid line in Fig. 8 (a)) is higher than that of untreated PET sheet after lamination (broken line in Fig. 6 (a)). This result shows that HLEBI activates the PE and PET surface. The active PE and PET attracts the oxygen atoms from atmospheric molecules with increasing oxygen content.

On the contrary, the active PE easily adheres the PET with decreasing the oxygen content on PE surface. Based on the both reaction, the adhesive force was increased. Therefore, although hot-pressing easily formed a tangling at interface generates the weak adhesion for untreated samples, both HLEBI and hot-pressing probably generates the chemical bonds, which induces the strong adhesion for different polymer laminated samples irradiated with optimal dose. Therefore, HLEBI prior to hot-press at near melting point induces the strong adhesion of different PE/PET polymers, which is caused by cross-linking with chemical bonding.

\subsection{Photos of optical stereomicroscope and XRD}

Figure 7 shows optical micrographs of peeled surface of PE and PET. As shown in Fig. 7 (a), mm-order scale rough-

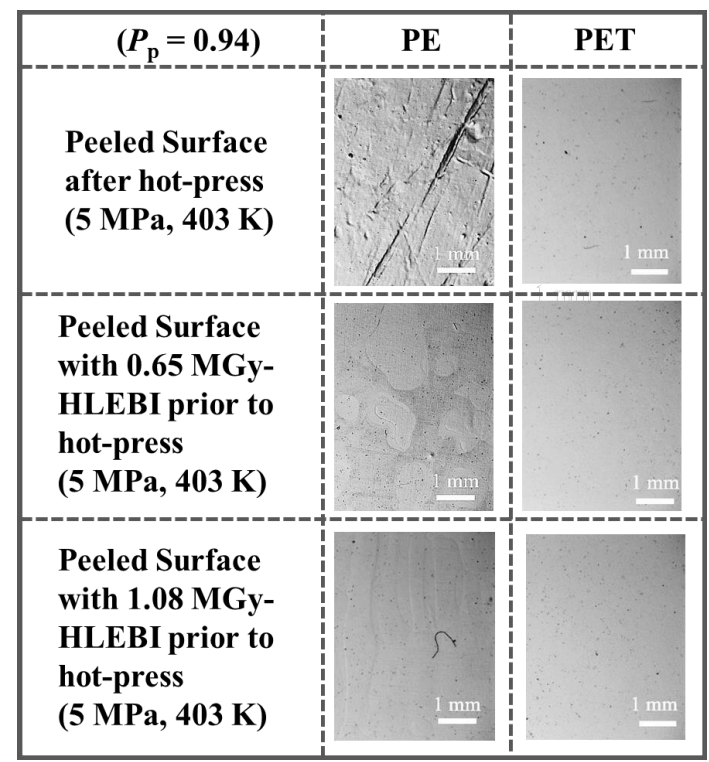

Fig. 7 Photos of optical stereomicroscope of peeled surface of PE (a) and PET (b) lamination sheets untreated and treated by HLEBI dose of 0.65 and 1.08 MGy prior to assembly and hot-pressed at $403 \mathrm{~K}$.

ness with cavities, islands and scratches can be remarkably seen on the surface of the PE sample untreated, whereas smooth peeled surface with and without peeling sign is clearly observed for the samples treated by HLEBI. The hot-press filled surface space and deforms the interface layer with each polymer tangling of PE/PET. HLEBI mainly cuts the polymers with active terminated atoms with dangling bonds. Thus, HLEBI prior to hot-press (5 MPa, $403 \mathrm{~K}$ ) enhances the density of cross-linking, that is, tangling of PE/PET polymers with chemical bonds at interface. The mm-order scale roughness with cavities, islands and scratches on the surface of the PE sample untreated in Fig. 7 can be explained because of the lack of deformation without cross-linked bonding sites. On the contrary, the smooth peeled surface with and without peeling sign observed for PE samples treated by HLEBI prior to hot-press in Fig. 7 can be explained because of deformation flow with cross-linking sites at the PE/PET interface layer. On the other hand, no obvious difference for PET samples is obtained in change regardless of HLEBI treatment, as shown in Fig. 7.

Figure 8 shows XRD results of peeled surface of PE (a) and PET (b), together with crystallinity against HLEBI dose. Based on the angle ( $2 \theta)$ of main peak of the PE sheet in Fig. 8 (a), the hot-press increases the $2 \theta$ of the peeled sheet of PE. It is because the residual compressive stress shortens the mean atomic distance of PE. On the contrary, 0.65 MGy-HLEBI prior to hot-press decreases $2 \theta$ and the increases the mean atomic distance of the peeled sheet of PE, since the residual tensile stress induced by peeling is larger than that of the residual compressive stress induced by hot-press. Namely, 0.65 MGy-HLEBI prior to hot-press improves the adhesive force which is mainly evaluated by the residual tensile stress induced by peeling, larger than the residual compressive stress induced by hot-press.

On the other hand, $1.08 \mathrm{MGy-HLEBI}$ prior to hot-press slightly increases the $2 \theta$ and slightly shrinks the mean atomic distance of the peeled sheet of PE. Since the residual com- 


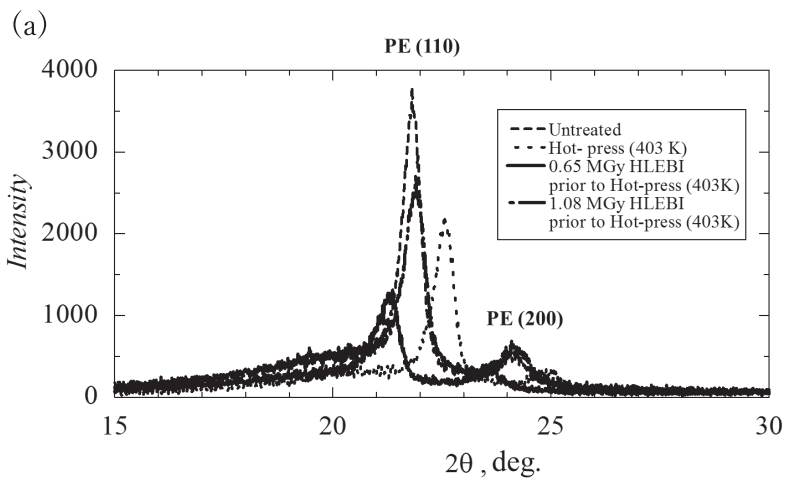

(b)

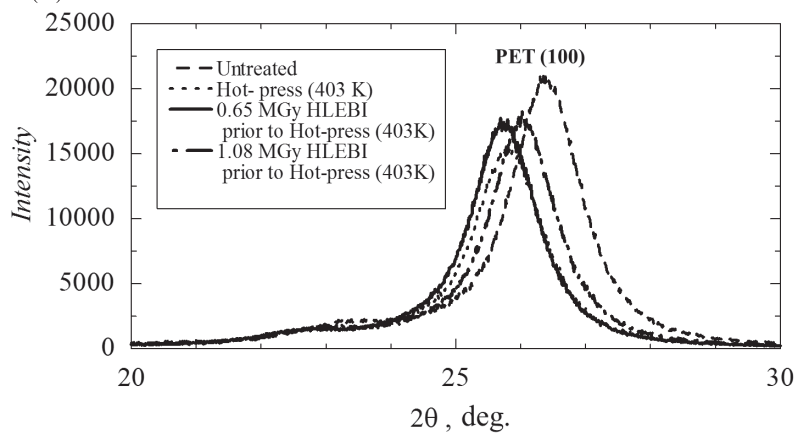

(c)

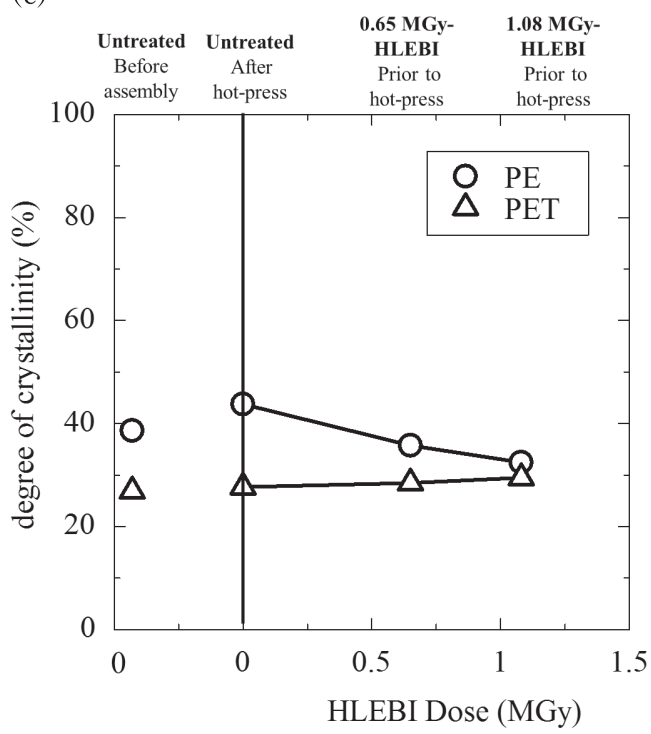

Fig. 8 XRD peaks of peeled surface of PE (a) and PET (b) lamination sheets untreated and treated by HLEBI dose of 0.65 and 1.08 MGy prior to assembly and hot-pressed at $403 \mathrm{~K}$, together with degree of crystallinity against HLEBI dose. (a) PE, (b) PET, (c) degree of crystallinity.

pressive stress induced by hot-press is slightly larger than that of the residual tensile stress induced by peeling, it is possible that 1.08 MGy-HLEBI prior to hot-press decreases the adhesive force smaller than that of $0.65 \mathrm{MGy}-\mathrm{HLEBI}$ prior to hotpress.

Based on the angle $(2 \theta)$ of main peak of the PET sheet in Fig. 8 (b), the hot-press increases the $2 \theta$ and slightly shortens the mean atomic distance of the peeled sheet of PET. It can be explained that the residual compressive stress induced by hotpress is slightly larger than that of the residual tensile stress induced by peeling.

On the contrary, 1.08 MGy-HLEBI prior to hot-press decreases $2 \theta$ and the increases the mean atomic distance of the peeled sheet of PET, since the residual tensile stress induced by peeling is larger than that of the residual compressive stress induced by hot-press. Namely, 1.08 MGy-HLEBI prior to hot-press improves the adhesive force which is mainly evaluated by the residual tensile stress induced by peeling, larger than the residual compressive stress induced by hotpress.

On the other hand, the $2 \theta$ of PET with 0.65 MGy-HLEBI prior to hot-press is equal to that of untreated, since the residual compressive stress induced by hot-press is equal to that of the residual tensile stress induced by peeling.

Figure 8 (c) shows the changes in degree of crystallinity evaluated by XRD peaks dose of peeled surface of PE (a) and PET (b) lamination sheets untreated and treated by HLEBI dose of 0.65 and 1.08 MGy prior to assembly and hot-pressed at $403 \mathrm{~K}$ against HLEBI dose, when the crystallinity degree assumes to be the volume fraction of hard segments with crystalline perfection. The crystalline degree is from 32.0 to $44.0 \%$ for PE and from 26.0 to $44.0 \%$ for PET. The hot-press increases crystalline degree from 39.5 to $43.5 \%$ for PE and slightly increases it from 27.0 to $27.55 \%$ for PET. On the other hands, HLEBI prior to hot-press decreases the crystalline degree from 39.5 to $43.5 \%$ for PE and slightly increases it from 27.0 to $27.55 \%$ for PET.

\subsection{Tensile stress $(\sigma)$ - strain ( $(\varepsilon)$ curves of PE and PET after peeling test}

As shown in Fig. 4 , the maximum ${ }^{\circ} F_{\mathrm{p}}\left(16.8 \mathrm{~N} \cdot \mathrm{m}^{-1}\right.$ and $86.8 \mathrm{~N} \cdot \mathrm{m}^{-1}$ ) are about 20 and 5.4 times larger compared to that of untreated samples $\left(0.85 \mathrm{~N} \cdot \mathrm{m}^{-1}\right.$ and $\left.16.0 \mathrm{~N} \cdot \mathrm{m}^{-1}\right)$ for low- and high- $P_{\mathrm{p}}$ of 0.06 and 0.94 of $1.08 \mathrm{MGy}-$ and 0.65 MGy-HLEBI samples, respectively. Thus, the influence of HLEBI-dose on tensile mechanical properties of each PE and PET has been studied. Figure 9 shows tensile stress $(\sigma)-$ strain $(\varepsilon)$ curves of PE and PET after peeling test. When the slope of $\sigma-\varepsilon$ curves $(\mathrm{d} \sigma / \mathrm{d} \varepsilon)$ reaches zero, the tensile strength $\left(\sigma_{\mathrm{b}}\right)$ can be defined at its corresponding strain $\left(\varepsilon_{\mathrm{b}}\right)$. As shown in Fig. 9 (a), the small dose of 0.65 MGy-HLEBI apparently enhances $\sigma_{\mathrm{b}}$ from 14.3 $\mathrm{MPa}$ to $17.0 \mathrm{MPa}$ and $\varepsilon_{\mathrm{b}}$ from 0.005 to 0.016 higher than those of PE untreated. Furthermore, $1.08 \mathrm{MGy}-\mathrm{HLEBI}$ slightly increases the $\varepsilon_{\mathrm{b}}$ from 0.016 to 0.030 , although the large dose of 1.08 MGy-HLEBI slightly decreases the $\sigma_{\mathrm{b}}$ from 17.0 MPa to 15.6 MPa for PE. Namely, HLEBI from 0.65 MGy to $1.08 \mathrm{MGy}$ improves the ductility of PE.

On the other hand, the small dose of 0.65 MGy-HLEBI slightly and radically decreases the $\sigma_{\mathrm{b}}$ from $135 \mathrm{MPa}$ to $125 \mathrm{MPa}$ and $\varepsilon_{\mathrm{b}}$ from 0.016 to 0.006 for PET, respectively, as shown in Fig. 9 (b). In addition, large dose of 1.08 MGyHLEBI apparently decreases both $\sigma_{\mathrm{b}}$ from 125 to $70 \mathrm{MPa}$ and $\varepsilon_{\mathrm{b}}$ from 0.006 to 0.003 for PET. Namely, HLEBI from $0.65 \mathrm{MGy}$ to $1.08 \mathrm{MGy}$ decays the ductility of PET, the $\sigma_{\mathrm{b}}$ of PET is 5 times strength that of PE. Thus, the fracture should be through inside of PE polymer, when the PE/PET interface adhesion in strength than the $\sigma_{\mathrm{b}}$ of PE.

It is shown that even if the adhesive peeling strength increases, the strength of the material itself does not always increase. Namely, the increase of the adhesive peeling strength is achieved independently to the strength of the material itself. 
As shown in Fig. 9, HLEBI from 0.65 MGy to $1.08 \mathrm{MGy}$ improves the ductility of PE, whereas it decays the ductility of PET. HLEBI of $0.65 \mathrm{MGy}$ improves the strength of PE, whereas HLEBI of 1.08 MGy apparently decays the strength of both PE and PET. When the peeling occurs at near interface of PE/PET lamination, both elastic and plastic deformations of PE probably occur. Since the strength values of PET with and without HLEBI are extremely higher than that of $\mathrm{PE}$, the elastic deformation always occurs in PET of laminations. Thus, large surface changes of the PET samples before and after peeling cannot be observed as shown in Fig. 9.

\subsection{The statistically lowest adhesive energy}

In order to obtain the statistically lowest peeling stress for safety design, the lowest ${ }^{\circ} F_{\mathrm{p}}$ value at $P_{\mathrm{p}}=0\left(F_{\mathrm{s}}\right)$ is assumed to be attained from the adaptable relationship of the 3 -parameter Weibull equation iterating to the high correlation coefficient $(f)$. The $P_{\mathrm{p}}$ depends on the risk of rupture $\left(\left[{ }^{\mathrm{o}} F_{\mathrm{p}}-F_{\mathrm{s}}\right] / F_{\mathrm{III}}\right) .{ }^{16)}$

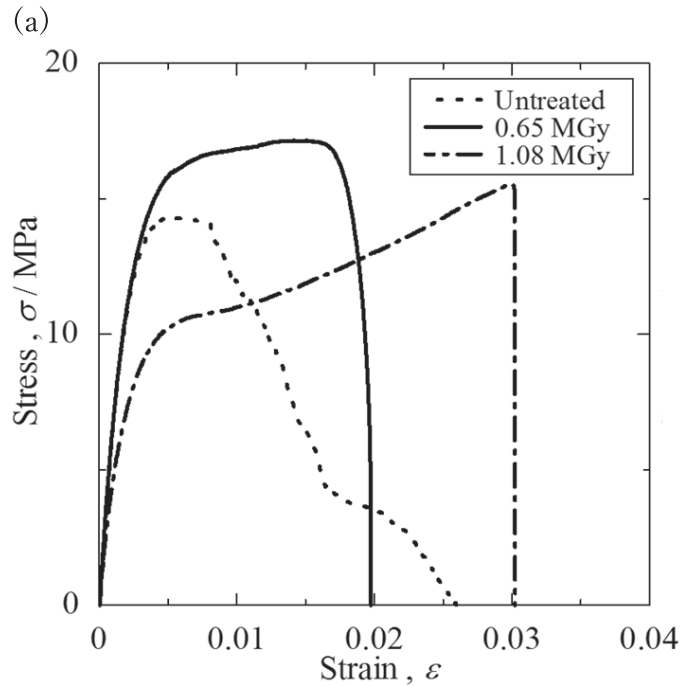

(b)

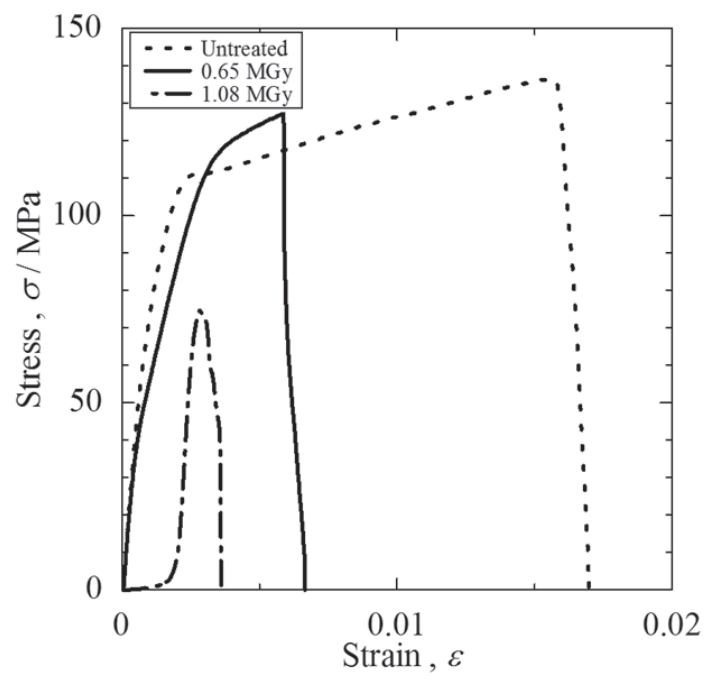

Fig. 9 Tensile stress $(\sigma)$ - strain $(\varepsilon)$ curves of peeled sheets of PE (a) and PET (b) untreated and separately treated by HLEBI dose of 0.65 and $1.08 \mathrm{MGy}$ prior to assembly and hot-pressed at $403 \mathrm{~K}$. Here, the samples are recorded at the highest ${ }^{\circ} \mathrm{F}_{\mathrm{p}}$ values at the highest $P_{\mathrm{p}}$ of PE/PET laminated sheets. (a) PE, (b) PET.

$$
P_{\mathrm{p}}=1-\exp \left[-\left(\left[{ }^{\mathrm{o}} F_{\mathrm{p}}-F_{\mathrm{s}}\right] / F_{\mathrm{III}}\right)^{m}\right]
$$

The linear relationship can be converted from eq. (6), as follows. ${ }^{6,16-21)}$

$$
\ln \left[-\ln \left(1-P_{\mathrm{p}}\right)\right]=m \ln \left[\left({ }^{\mathrm{o}} F_{\mathrm{p}}-F_{\mathrm{s}}\right) / F_{\mathrm{III}}\right]
$$

In predicting the $F_{\mathrm{s}}$, coefficient $(m)$ and constant $\left(F_{\mathrm{III}}\right)$ are the key parameters. When the term $\ln \left[-\ln \left(1-P_{\mathrm{p}}\right)\right]$ is zero, $P_{\mathrm{p}}$ is 0.632 and $\left({ }^{\circ} F_{\mathrm{p}}-F_{\mathrm{s}}\right)=F_{\text {III }}$. The $F_{\mathrm{III}}$ value is determined, when the ${ }^{\circ} F_{\mathrm{p}}$ value at $P_{\mathrm{p}}=0.632\left({ }^{\mathrm{o}} F_{\mathrm{p}}(0.632)\right)$ is equal to $\left(F_{\mathrm{III}}+F_{\mathrm{s}}\right)$ value. When $P_{\mathrm{p}}=0$, the required ${ }^{\circ} F_{\mathrm{p}}$ value to evaluate new structural materials is defined as the $F_{\text {s. }}$.

Figure 10 plots the iteration to obtain the highest correlation coefficient $(f)$ with respect to the potential adhesive force of peeling ${ }^{\circ} F_{\mathrm{S}}$ value $\left({ }^{e} F_{\mathrm{S}}\right)$ estimated from the logarithmic form.

Figure 11 illustrates the linear relationships between $\ln$ $\left({ }^{\circ} F_{\mathrm{p}}-F_{\mathrm{s}}\right)$ and $\ln \left[-\ln \left(1-P_{\mathrm{p}}\right)\right]$. The values of $F_{\mathrm{III}}$ and $m$ are

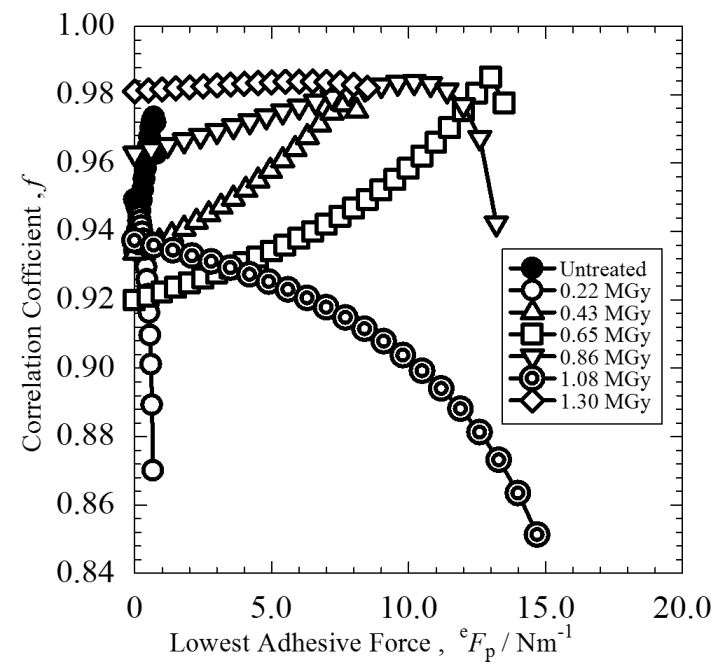

Fig. 10 Changes in correlation coefficient $(f)$ of eq. (1) against the potential ${ }^{\mathrm{o}} F_{\mathrm{s}}$ value $\left({ }^{\mathrm{e}} F_{\mathrm{s}}\right)$ for PE/PET laminated sheets at each absorbed dose of HLEBI. The expression of markers is the same as defined in the Fig. 4, respectively.

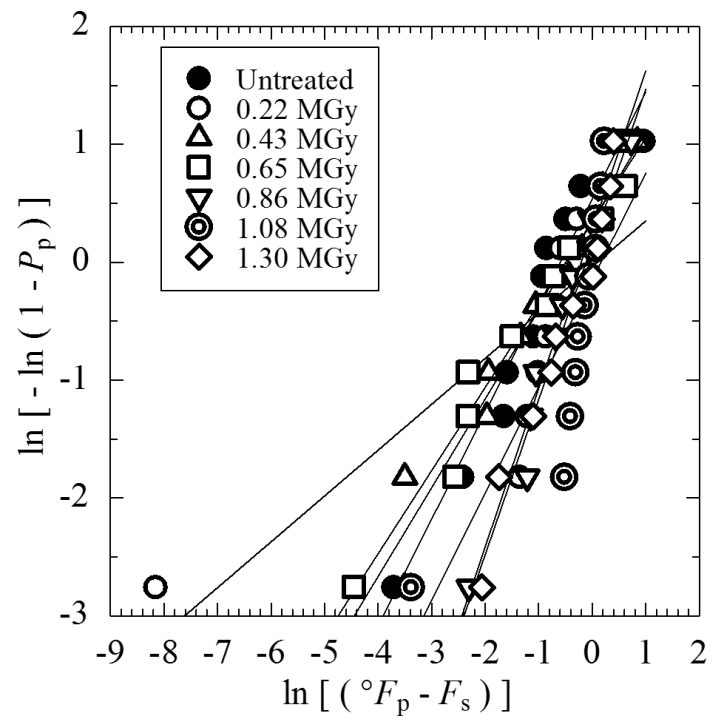

Fig. 11 Liner relationships between $\ln \left[-\ln \left(1-P_{\mathrm{p}}\right)\right]$ and $\ln \left({ }^{\circ} F_{\mathrm{p}}-F_{\mathrm{s}}\right)$ for PE/PET laminated sheets at each absorbed dose of HLEBI. The expression of markers is the same as defined in the Fig. 3, respectively. 
determined by the least-squares best fit method. The $m$ value is estimated by the slope of the relationship when ${ }^{e} F_{\mathrm{s}}=F_{\mathrm{s}}$.

Figures 3 and 4 show $F_{\mathrm{S}}$ is always lower than the experimental ${ }^{\circ} F_{\mathrm{p}}$ value. The HLEBI from 0.43 MGy to $1.30 \mathrm{MGy}$ improves the $F_{\mathrm{S}}$ values of the PE/PET laminated sheets over that of the untreated. The 1.08 MGy-HLEBI apparently enhances the $F_{\mathrm{s}}$ from $0.70 \mathrm{~N} \cdot \mathrm{m}^{-1}$ for the untreated to $16.0 \mathrm{~N} \cdot \mathrm{m}^{-1}$, as well as at low $P_{\mathrm{p}}$ of 0.06 (the lowest experimental ${ }^{\circ} F_{\mathrm{p}}$ ) from $0.70 \mathrm{~N} \cdot \mathrm{m}^{-1}$ for the untreated to $16.8 \mathrm{~N} \cdot \mathrm{m}^{-1}$. Consequently, HLEBI enhances the safety level (reliability) of PE/ PET laminated sheets. This indicates HLEBI induced adhesion can be applied to practical articles with sterilization without volatilization, when the adhesive force of peeling resistivity is less than $16.0 \mathrm{~N} \cdot \mathrm{m}^{-1}$.

\section{Conclusions}

2-layer Polyethylene (PE) and Polyethylene Terephthalate (PET) (PE/PET) laminated sheets were prepared by a new adhesion method, a double-step treatment consisting of applying homogeneous low energy electron beam irradiation (HLEBI) prior to hot-press under $5 \mathrm{MPa}$ at $403 \mathrm{~K}$. Although the weak adhesion of PE/PET laminated sheets with hotpress had been observed, the strong adhesion of the PE/PET laminated sheets was found from the new double-step treatment applying low dose $\leqq 1.30$ MGy-HLEBI of the 2-layer assembled PE/PET prior to hot-press lamination under $5 \mathrm{MPa}$ at $403 \mathrm{~K}$.

(1) The double-step treatment applying increased HLEBI dose from 0.22 MGy to 1.30 MGy prior to hot-press enhanced the adhesive force of peeling resistance $\left({ }^{\circ} F_{\mathrm{p}}\right)$ at peeling probability $\left(P_{\mathrm{p}}\right)$ of $0.06,0.50$ and 0.94 .

(2) Comparing the adhesive force at high $P_{\mathrm{p}}\left(P_{\mathrm{p}}=0.94\right)$, ${ }^{\mathrm{o}} F_{\mathrm{p}}=16.0 \mathrm{~N} \cdot \mathrm{m}^{-1}$ and ${ }^{\mathrm{o}} F_{\mathrm{p}}=86.8 \mathrm{~N} \cdot \mathrm{m}^{-1}$ were obtained for untreated samples and $0.65 \mathrm{MGy}$-HLEBI samples, respectively. Thus, ${ }^{\circ} F_{\mathrm{p}}$ of $0.65 \mathrm{MGy}$-HLEBI samples were about 5.4 times larger compared to that of untreated samples.

(3) Based on the 3-parameter Weibull equation, the lowest ${ }^{\mathrm{o}} F_{\mathrm{p}}$ value at the lowest $P_{\mathrm{p}}$ of zero $\left(F_{\mathrm{s}}\right)$ could be estimated. The double-step treatment applying HLEBI up to $1.08 \mathrm{MGy}$ prior to hot-press apparently improved the $F_{\mathrm{s}}$. The maximum $F_{\mathrm{s}}$ value of the PE/PET laminated sheets with hot-press after 1.08 MGy-HLEBI dose was $16.0 \mathrm{~N} \cdot \mathrm{m}^{-1}$. Consequently, the double-step treatment of applying 1.08 MGy-HLEBI prior to hot press improved the safety level.

(4) The maximum peeling adhesive force value at low $P_{\mathrm{p}}$ (zero and 0.06) of the laminated sheet irradiated at 1.08 MGy were $16.0 \mathrm{~N} \cdot \mathrm{m}^{-1}$ and $16.8 \mathrm{~N} \cdot \mathrm{m}^{-1}$, respectively. However, the higher dose of the double-stop treatment applying more than $1.08 \mathrm{MGy}$ HLEBI apparently reduced the ${ }^{\circ} F_{\mathrm{p}}$ at each $P_{\mathrm{p}}$. Therefore, with careful consideration to dose level, the double-step treatment applying HLEBI prior to hot-press proved a useful method for strong and quick lamination of PE and PET with sterilization without the use of glue.

(5) Based on the XPS results, although hot-pressing easily formed a tangling at interface generates the weak adhesion for untreated samples, both HLEBI and hot-pressing probably generates the chemical bonds, which induces the strong adhesion for different polymer laminated samples irradiated with optimal dose. This can be explained by the adhesion en- ergy from cross-linking between PE/PET being stronger than the cohesive force of PE and PET itself.

(6) Based on the tensile stress $(\sigma)-$ strain $(\varepsilon)$ curves and optical micrographs of peeled surface of PE and PET after peeling test, the smooth peeled surface with and without peeling sign observed for PE samples treated by HLEBI prior to hot-press could be explained because of deformation flow with cross-linking sites at the PE/PET interface layer. On the other hand, no obvious difference for PET samples was obtained in change regardless of HLEBI treatment.

(7) The strengthening mechanism shift by elevating the hot-press temperature from under melting point to over melting point is probably dominated by polymers tangling at the PE/PET adhesion interface. Therefore, we conclude that HLEBI induced chemical bonds, hot-press induced tangling, and the additive strengthening of tangling and cross-linking can be explained.

\section{Acknowledgements}

This work was partly supported by JSPS Core-to-Core Program, A. Advanced Research Networks, "International research core on smart layered materials and structures for energy saving", as well as Eye Electron Beam Co. Ltd and Prof. A. Tonegawa of Tokai University.

\section{REFERENCES}

1) S. Affatato, M. Zavalloni, P. Taddei, M. Di Foggia, C. Fagnano and M. Viceconti: Tribol. Int. 41 (2008) 813-822.

2) B. Marczis and T. Czigany: Periodica Polytechnica Ser. Mech. Eng. 46 (2002) 117-126.

3) Journal of the Adhesion Society of Japan 37 (2001) 217-223.

4) K. Oguri, N. Iwataka, A. Tonegawa, Y. Hirose, K. Takayama and Y. Nishi: J. Mater. Res. 16 (2001) 553-557.

5) M. Faudree and Y. Nishi: Mater. Trans. 53 (2012) 1412-1419.

6) Y. Nishi, M. Uyama, H. Kawazu, H. Takei, K. Iwata, H. Kudoh and K. Mitsubayashi: Mater. Trans. 53 (2012) 1657-1664.

7) Y. Nishi, H. Kawazu, H. Takei, K. Iwata, H. Kudoh and K. Mitsubayashi: Mater. Trans. 52 (2011) 1943-1948.

8) C. Kubo, T. Okada, M. Uyama, M. Kanda and Y. Nishi: Mater. Trans. 55 (2014) 1742-1749.

9) R. Suenaga, M. Kanda, N. Hironaka and Y. Nishi: J. Jpn. Inst. Metals 72 (2008) 35-38.

10) T. Shimaru: Tech. on Adhesion \& Sealing 3 (1959) 121-130.

11) K. Oguri, K. Fujita, M. Takahashi, Y. Omori, A. Tonegawa, N. Honda, M. Ochi, K. Takayama and Y. Nishi: J. Mater. Res. 13 (1998) 33683371.

12) C. Kubo, A. Yagi, M. Kanda and Y. Nishi: Mater. Trans. 56 (2015) 529533.

13) C. Kubo, M. Kanda and Y. Nishi: Mater. Trans. 56 (2015) 1517-1522.

14) C. Kubo, M. Kanda, K. Miyazaki, T. Okada, M.C. Faudree and Y. Nishi: Mater. Trans. 56 (2015) 1821-1826.

15) M. Kanda, K. Yuse, B. Guiffard, L. Lebrun, Y. Nishi and D. Guyomar: Mater. Trans. 53 (2012) 1806-1809.

16) W. Weibull: Ingeniörs vetenskaps akademien, nr. 153 (Generalstabens litografiska anstalts förlag, Stockholm, (1939) pp. 16-22.

17) H. Takei, M. Salvia, A. Vautrin, A. Tonegawa and Y. Nishi: Mater Trans. 52 (2011) 734-739.

18) K. Iwata and Y. Nishi: Mater. Trans. 49 (2008) 2058-2062.

19) Y. Nishi, H. Kobayashi and M. Salvia: Mater. Trans. 48 (2007) 19241927.

20) N. Tsuchikura, M.C. Faudree and Y. Nishi: Mater. Trans. 54 (2013) 371-379.

21) H. Takei, K. Iwata, M. Salvia, A. Vautrin and Y. Nishi: Mater. Trans. 51 (2010) 2259-2265. 